\title{
Frontières
}

\section{Gilles Ernst (dir.), Ce que la littérature sait de la mort, Dossier du Magazine Littéraire, novembre 2012, p. 48-80}

\section{Hans-Jürgen Greif}

Volume 25, numéro 1, automne 2012

Le vieillissement et sa diversité

URI : https://id.erudit.org/iderudit/1018238ar

DOI : https://doi.org/10.7202/1018238ar

Aller au sommaire du numéro

Éditeur(s)

Université du Québec à Montréal

ISSN

1916-0976 (numérique)

Découvrir la revue

Citer ce compte rendu

Greif, H.-J. (2012). Compte rendu de [Gilles Ernst (dir.), Ce que la littérature sait de la mort, Dossier du Magazine Littéraire, novembre 2012, p. 48-80].

Frontières, 25(1), 186-187. https://doi.org/10.7202/1018238ar

Ce document est protégé par la loi sur le droit d'auteur. L'utilisation des services d'Érudit (y compris la reproduction) est assujettie à sa politique d'utilisation que vous pouvez consulter en ligne.

https://apropos.erudit.org/fr/usagers/politique-dutilisation/
Cet article est diffusé et préservé par Érudit.

Érudit est un consortium interuniversitaire sans but lucratif composé de l’Université de Montréal, l'Université Laval et l'Université du Québec à Montréal. Il a pour mission la promotion et la valorisation de la recherche. https://www.erudit.org/fr/ 
Gilles Ernst (dir.)

\section{Ce que la littérature sait de la mort.}

Dossier du Magazine Littéraire, novembre 2012, p. 48-80

\section{Hans-Jürgen Greif}

Voici quinze articles sur la camarde, vue par des romanciers, des philosophes et trois dramaturges, sans inclure les poètes. Dès le premier texte, on comprend combien a été écrit sur la mort, individuelle ou collective. Déferlent sur le lecteur quantité de noms célèbres, de Voltaire à Valéry, jusqu'à Jenni (déjà membre du club sélect). Chaque collaborateur disposait de deux pages, incluant photos, tableaux, documents. Parfois, les réflexions ont été comprimées à l'extrême, alors qu'ailleurs, les auteurs ont respiré plus librement. (Proposition: passer par-dessus le diktat du graphisme.)

Alors, quel profil la littérature dessine-t-elle de la mort? Dans les deux contributions fondamentales de Gilles Ernst, pilote du dossier - la revue a fait appel aux meilleurs spécialistes dans le domaine - , il est frappant de suivre le traitement du sujet entre permanence et innovation, autrement dit, entre mort individuelle (Le roi se meurt, Ionesco, 1962) et collective (Le Rivage des Syrtes, Gracq, 1951). En découlent cinq tendances: une vaste interrogation du sens de la mort, son rapport avec la politique, la nature mortifère de l'érotisme, I'influence des Hegel et Schopenhauer, les récits de la mort d'un proche, sans oublier le suicide, qui se démocratise pendant les $\mathrm{XIX}^{\mathrm{e}}$ et $\mathrm{XX}$ e siècles et mène à des descriptions morbides, portant une aura noire (relire la mort de Madeleine de Sainte Colombe, par Quignard).

Avec ses études sur la nécrophilie ainsi que la représentation de la mort au temps du décadentisme et du symbolisme, Patrick Bergeron fait découvrir des livres incontournables, Le Nécrophile de Gabrielle Wittkop (1972), époustouflant par le contenu et la langue, ainsi qu'Un enfant de Dieu de Cormac McCarthy, avant de se lancer dans son domaine préféré, le décadentisme, où la mort devient jeu, comédie. (On attend 
avec impatience I'essai de P. Bergeron sur le traitement de la mort chez Barrès et Hofmannsthal.)

À juste titre, Marie-Claude Hubert soutient que, contrairement au roman, les dramaturges ont rarement eu recours à la mort sur la scène, jusqu'à l'arrivée de Comédie (Beckett), du Roi se meurt (Ionesco), dans sa marche vers le «Grand Rien», et de Genet, chez qui on meurt, métaphore superbe, en traversant le papier des Paravents, pour rire de la bêtise humaine dans la guerre d'Algérie.

Après I'émouvant texte de Joseph Lévy et Lucie Quévillon sur le sida, la mise en scène de sa mort par Hervé Guibert, le rythme ralentit: Catriona Seth analyse Les liaisons dangereuses et Martine Courtois I'œuvre du médecin et archéologue Victor Segalen. Jean-François Louette parle d'un Sartre aux attitudes changeantes face à la mort. Avec Huis clos, la littérature permet au philosophe de passer, dans et par l'imaginaire, de l'autre côté.

La mort du père pendant la Grande Guerre demeure l'événement pivot chez bien des écrivains, comme le démontrent Éric Briot pour Giono (Le Hussard sur le toit, 1951) et Michel Bertrand pour Simon (La Route des Flandres, 1960). Ici, on aurait aimé entendre au moins une voix d'outre-Rhin, celle de Jünger, dans Orages d'acier. Dans ses réflexions sur Derrida et la mort de sa mère, Lawrence $D$. Kritzman se concentre sur Circonfessions, où se trouve la phrase suivante, ambiguë: «Depuis 59 ans je ne sais qui pleure ma mère ou moi », proche du Livre de ma mère (Cohen, 1954).

Que reste-t-il de ce kaléidoscope de la mort? Émotions, étonnements, envie de relire et d'argumenter avec les auteurs des articles. Surtout: savoir que la littérature, quoi qu'il arrive, continuera à vivre, sous forme de livres, physiques ou virtuels. La littérature et ceux qui la font, connaissent la mort sous toutes ses coutures. Après Edipe roi, on a envie de dire avec William Marx: «Cassandre, n'est-elle pas I'autre nom de la fiction et de la littérature: celle qui dit vrai sans qu'on ose y croire?» 